\title{
Covid-19: Charities call for clear advice after "utter mess" of shielding texts
}

\author{
Ingrid Torjesen
}

London

Leading healthcare charities have written to the UK government asking for people who have been told to shield because they are most at risk from the effects of covid-19 to be given "clear, consistent advice" after the "utter mess" caused by incorrect communications.

The British Liver Trust, Asthma UK, and the British Lung Foundation are among nearly 50 charities that signed the open letter, which said that these patients needed to know what to expect and how to protect themselves once shielding was lifted. The wider group of vulnerable people who had not been asked to "shield" but would be at greater risk as lockdown was lifted also needed advice, the letter said.

The call for clarity follows reports from patients in England with conditions such as severe asthma, lung disease, and cancer who said that they had received text messages informing them that they had been removed from the official shielding list without their GP's knowledge. The problem mirrors that seen when lockdown was imposed in March, ${ }^{1}$ when some patients at very high risk did not receive messages to shield, while tens of thousands of others who did not need to shield, including some deceased patients, ${ }^{2}$ did receive them. ${ }^{3}$

The official texts sent from the Gov.uk website on 22 May said that the patients' GP or specialist had recommended that they no longer needed to shield and that, if they were receiving food deliveries through the national shielding service, these would be stopped.

\section{Evidence and transparency}

Alison Cook, director of external affairs at Asthma UK and the British Lung Foundation, said, "We have heard from people with severe asthma and lung disease who have been alarmed about receiving official text messages with no explanation. Some are saying their GP had also not been told."

Vanessa Hebditch, director of communications and policy at the British Liver Trust, said, "Nobody should have received a text as the first piece of communication. Some people who have had the text are definitely in the extremely vulnerable category, so following its advice could put them at risk. Our advice if you do receive a text is to continue to shield.

"We are also aware that the electronic records held by GPs have also automatically been changed when people have received this text."

Hebditch told The BMJ that transparency was also needed around the evidence informing the government's shielding policy. She said, "With new information and research emerging and novel data providing better evidence on the epidemiology and behaviour of the disease, we would like to understand the process of evidence review being used to inform and adapt shielding guidance."

A government spokesperson commented, "Clinicians are identifying people who had initially been advised to shield from coronavirus but no longer need to do so. Where this is the case, the person should be informed by their clinician that they are being removed from the shielded patient list. Clinicians have been given guidance to help them communicate this." The spokesperson added that the text message was to confirm that support from the national shielding service would end.

Cook branded the communication strategy over shielding "an utter mess."

\section{Changing guidance}

Martin Marshall, chair of the Royal College of General Practitioners, said, "We know that judging who is extremely clinically vulnerable is complex —and that as we learn more about the covid-19 virus, this guidance will change and be relevant to different people. However, it is important that, as guidance changes and patients are either added or removed from 'shielding lists' based on conditions they have or medication they are taking, GPs and relevant specialists are advised about this.

"This is so that doctors can communicate effectively with their patients, if they have questions-but also so that we can advise whether there are other circumstances why, based on our clinical judgment, a patient should 'shield."'

Patients who have been told that they should not shield and believe that they need to, or vice versa, should contact their GP or hospital specialist, said Marshall. 


\section{Algorithm helps patients with rare genetic diseases}

Doctors at London's Great Ormond Street Hospital (GOSH) have developed an algorithm (https://is.gd/covid19 gosh) to help patients determine whether they are in the very high risk category for covid-19 and should be shielding. Elizabeth Forsythe and Lara Menzies, specialist registrars in clinical genetics at GOSH, said that they had taken this action after feedback from patient support groups suggested that many people with rare diseases were confused and scared about whether they should shield.

Some genetic disorders that confer a high risk were not included in the official list of diagnoses for shielding because they were so rare, whereas others were on the list even though a diagnosis conferred no increased risk or was limited to certain patients, explained Frances Elmslie, president of the UK Clinical Genetics Society and consultant clinical geneticist at St George's, University of London.

For example, patients with a diagnosis of tuberous sclerosis complex (TSC) were sent a shielding text and letter even though most were not at increased risk at all, she said. "During consultations, I am still finding families that have been shielding because they have taken the advice at face value," she explained. "Children with this condition can have learning difficulties and very challenging behaviour so remaining at home has been difficult, especially when they didn't need to. Conversely, some patients with TSC are high risk and did not receive a letter because their diagnosis does not appear in their electronic record."

The algorithm is based on an array of official guidelines. Feedback from GPs and clinical genetics doctors who have used it has been "overwhelmingly positive," Forsythe and Menzies confirmed.

They added that the aim was to open a conversation between the person with a rare disease and the primary physician, who ultimately makes the decision of putting patients on the shielding list or removing them. "The tool does not replace the advice of the primary physician who has a holistic overview of the patient," said Forsythe and Menzies. "Each trust has a person who can add or remove people on the shielding list."
1 Chalmers V. More than 100000 people were WRONGLY told they were "extremely vulnerable" to the deadly coronavirus and needed to self-isolate until the end of June. MailOnline 2020 May 11. https://www.dailymail.co.uk/news/article-8292553/More-100000-people-wrongly-told-extremely-vulnerable-coronavirus.html.

2 NHS Digital. Coronavirus letters sent in error to deceased patients: a message to family members affected. 24 Mar 2020. https://digital.nhs.uk/news-and-events/latest-news/ coronavirus-letters-sent-in-error-message-to-family-members.

3 Kmietowicz Z. Covid-19: Highest risk patients are asked to stay at home for 12 weeks. BMJ 2020;368:m1170. 10.1136/bmj.m1170 32205309

This article is made freely available for use in accordance with BMJ's website terms and conditions for the duration of the covid-19 pandemic or until otherwise determined by BMJ. You may use, download and print the article for any lawful, non-commercial purpose (including text and data mining) provided that all copyright notices and trade marks are retained.

https://bmj.com/coronavirus/usage 